\title{
American Association of Clinical Endocrinologists-Update for 2019
}

\author{
Sandra Weber \\ President, American Association of Clinical Endocrinologists, Jacksonville, FL, USA
}

DOI: https://doi.org/10.17925/USE.2019.15.2.59

A S American Association of Clinical Endocrinologists (AACE) approaches its $29^{\text {th }}$ year, the association continues to experience an invigorating period of transformation. While elevating the profession of the clinical endocrinologist, AACE is improving best practices to evolve with the changing healthcare landscape. What remains the same is AACE'S mission to enhance the ability of its membership to provide the highest quality of patient care.

\section{Keywords}

AACE, ACE, FACE, clinical endocrinology, EMBRAACE, congress, annual, endocrine practice, EmPower, SCOPE, diabetes emergency plan, CME

Disclosure: Sandra Weber has no conflicts of interest to declare.

Review Process: This is an opinion piece and, as such, has not undergone the journal's standard peer review process.

Compliance with Ethics: This article is an opinion piece and does not report on new clinical data, or any studies with human or animal subjects performed by any of the authors.

Authorship: The named author meets the Internationa Committee of Medical Journal Editors (ICMJE) criteria for authorship of this manuscript, takes responsibility for the integrity of the work as a whole, and has given final approval for the version to be published.

Received: October 17, 2019

Accepted: October 22, 2019

Citation: US Endocrinology. 2019;15(2):59-60

Corresponding Author: Sandra Weber,

American Association of Clinical Endocrinologists,

245 Riverside Avenue, Suite 200, Jacksonville,

FL 32202. E: media@aace.com

Support: No funding was received in the publication of this article.
American Association of Clinical Endocrinologists (AACE) is the world's largest organization to represent clinical endocrinologists with more than 6,900 members in the USA and 99 other countries. Members have access to educational programs, subscriptions to AACE publications, discount registration to AACE Annual Scientific \& Clinical Congress, scholarship and grant opportunities, advance notice of endocrine job opportunities, practice management support, and more. AACE also offers the opportunity for fellowship distinction through the Fellow of the American College of Endocrinology (FACE) program, which is available to AACE members in good standing who meet designated criteria. Additionally, each year, one FACE member is awarded the distinction of Master of the American College of Endocrinology.

In 2019, AACE Board of Directors implemented steps to reorient and improve its education programs. It is a top priority for AACE to remain the authority for education to the clinical endocrinologist. The AACE's in-person educational programs, online courses, and webinars help members earn continuing medical education (CME) credits and stay current with critical and relevant endocrine patient treatment issues. Over the past few years, steps were taken towards the redevelopment of several of these programs, including Endocrine University, and improvements were also made to sought-after courses and certifications. New programs like SCOPE, Successful Co-management between Primary Care and Endocrinology, were implemented.

Additionally, through AACE publications, members have access to innovative clinical endocrinology research, reports and the latest clinical care guidelines and algorithms. AACE's flagship publication is Endocrine Practice, the official peer-reviewed journal of AACE, which is published 12 times a year and contains original articles, review articles, commentaries, editorials and visual vignettes. AACE also publishes an annual report every May to inform members and the endocrine community about the progress of AACE and recent actions of the association's leadership. Furthermore, AACE publishes online news and newsletters to keep members informed of the latest updates relative to the field of endocrinology, including insurance carrier updates, compliance updates and news regarding drug recalls. Finally, AACE EmPower program continues to expand its reach to targeted patient populations through a variety of outreach activities, such as EmPower Magazine and My Diabetes Emergency Plan.

AACE continues to improve the membership experience and analyze engagement to enhance visability to members and their practices. For example, in 2019, the AACE completed its latest phase of digital transformation by launching a new website design, as well as a new association management system and content management system that will provide improved operational efficiency for the organization and an enhanced online experience for the endocrine community. AACE also recently launched two additional comprehensive resource centers-the AACE Lipids Resource Center and the AACE Bone Resource Center-to complement the existing AACE Diabetes Resource Center and AACE Obesity Resource Center. All four have become go-to sources of information and disease state education for physicians and other healthcare professionals worldwide. 
Currently, AACE is preparing for AACE 29 $9^{\text {th }}$ Annual Scientific \& Clinical Congress (EMBRAACE 2020), which will be held in Washington, D.C. from May 7-10, 2020. AACE Scientific \& Clinical Congress is a gathering of clinical endocrinologists and other healthcare professionals who come together yearly to learn more about the latest developments, research, devices and translational therapies. EMBRAACE 2020 will feature more than 100 educational sessions addressing the clinical topics that are relevant to practicing endocrinologists. Participants can select to attend the sessions that are most relevant to their practice. The meeting will also feature keynote speaker Tait Shanafelt, MD, Stanford Medicine's first chief wellness officer and a leading researcher on physician burnout. Finally, the meeting features AACE/ACE Awards, which are presented to individuals in the field of endocrinology, recognizing excellence in categories such as endocrine patient care, innovative treatments and therapies, and service to others.
Additionally, AACE serves as a unified voice for the professional concerns of endocrinologists at the local, regional and national level through active advocacy efforts, which address the policies that impact the practice of endocrinology and the well-being of patients. The cornerstone of AACE advocacy is the Key Contacts Program, which provides members with the support necessary to advance legislative priorities by working directly with congressional representatives to champion key issues. With many changes underway and on the horizon, what remains the same is the AACE's mission to enhance the ability of its membership of physicians, who specialize in endocrinology, diabetes, and metabolism, to provide the highest quality of patient care. Whether you are just beginning your education in endocrinology or transitioning into your career, AACE has the resources you need for your professional growth. Learn more about AACE member benefits and join AACE at www.aace.com. $\square$ 